\title{
EDITORIAL
}

\section{Program Akselerasi Penurunan Angka Kematian Ibu POGI Jabar: Zero Mother Mortality Preeclampsia (ZOOM)}

Moto: "preeklamsi bisa tetap ada tetapi ibu harus tetap bernyawa"

\author{
Adhi Pribadi ${ }^{1,2}$ \\ ${ }^{1}$ Divisi Kedokteran Fetomaternal Departemen Obstetri dan Ginekologi \\ RSUP Dr. Hasan Sadikin/FK Unpad \\ ${ }^{2}$ Koordinator Pendidikan POGI Jabar \\ Korespondensi: email: adhi@unpad.ac.id
}

\section{Pendahuluan}

Angka Kematian Ibu (AKI) merupakan salah satu indikator untuk melihat derajat kesehatan perempuan. Selain itu AKI merupakan salah satu target utama yang telah ditentukan oleh WHO sebagai indikator kesehatan suatu negara. ${ }^{1}$ Dari hasil survey yang dilakukan, AKI di Indonesia telah menurun dari waktu ke waktu, namun masih relatif tinggi dibandingkan negara Asia lainnya. Jumlah angka kematian ibu di Indonesia (angka nasional) tahun 1991 sebanyak 390 sedangkan pada tahun 2015 menurun mencapai 305/100.000 jumlah kelahiran hidup. ${ }^{2}$ Di sisi lain, angka kematian ibu Provinsi Jawa Barat tahun 2015 adalah sebanyak 823/100.000. ${ }^{3}$

Rendahnya kesadaran masyarakat tentang kesehatan ibu hamil menjadi faktor penentu angka kematian, meskipun masih banyak faktor yang harus diperhatikan untuk menangani masalah ini. Persoalan kematian yang terjadi antara lain pendarahan, preeklamsi-eklamsi dengan komplikasi, aborsi, dan infeksi. Namun, ternyata masih ada faktor lain yang cukup penting, yaitu pemberdayaan perempuan yang belum baik, latar belakang pendidikan, sosioekonomi keluarga, lingkungan masyarakat dan kebijakan publik. Kaum lelaki pun dituntut harus berupaya lebih aktif dalam segala permasalahan bidang reproduksi. Oleh karena itu, pandangan yang menganggap kehamilan adalah peristiwa alamiah perlu diubah secara sosiokultural agar perempuan dapat lebih mendapat perhatian dari masyarakat. Sangat diperlukan upaya peningkatan pelayanan perawatan ibu oleh pemerintah, swasta, maupun masyarakat lainnya terutama suami.

Kematian ibu disebabkan oleh hipertensi dalam kehamilan (HDK) secara global menempati nomor dua setelah kasus perdarahan, demikian pula di Indonesia. ${ }^{4}$ Pada tahun 2016 dalam rangka menunjang kegiatan penurunan angka kematian ibu, Perkumpulan Obstetri dan Ginekologi Indonesia (POGI) bersama Kantor Kementerian Kesehatan mengeluarkan Panduan Nasional Praktik Kedokteran (PNPK) tentang preeklamsi yang menjadi dasar untuk pembuatan standar pelayanan preeklamsi di seluruh Indonesia dan diharapkan mampu membantu mempercepat penurunkan AKI.

\section{Kegiatan utama Zero Mother Mortality Preeclampsia (ZOOM)}

Program ZOOM merupakan kegiatan yang dilakukan oleh POGI Cabang Jawa Barat sejak Maret tahun 2017, dengan visi menurunkan angka kematian ibu (AKI) serendah mungkin di provinsi Jawa Barat dengan melibatkan seluruh tenaga kesehatan. Preeklamsi merupakan sasaran pertama karena mempunyai karakteristik yang dapat dicegah, serta sarana dan prasarananya telah tersebar luas di provinsi Jawa Barat sehingga dapat dilakukan segera. Propinsi Jawa Barat adalah provinsi dengan jumlah penduduk terbanyak di Indonesia, sehingga bila Jawa Barat 
dapat menurunkan AKI secara signifikan akan berdampak pula pada AKI Indonesia secara nasional. Jawa Barat mempunyai data demografi sebagai berikut: jumlah penduduk 47.379.389 jiwa, perempuan 23.368.128 jiwa, jumlah perempuan produktif (15-39 tahun) 9.685.146 jiwa, luas wilayah $35.377,76 \mathrm{~km}^{2}$ dengan rasio penduduk per kilometer 1.339 jiwa. $^{5}$

\section{Alasan pilihan preeklamsi sebagai target pertama untuk menurunkan AKI}

1. Adanya metode deteksi dini

Deteksi dini didasarkan pada tiga hal utama yang difokuskan dan saling melengkapi satu sama lain..$^{6,7} 8$ sebagai berikut:

a. Riwayat medis atau faktor risiko sebelum kehamilan.

b. Kumpulan parameter biofisik seperti tekanan darah, kekakuan arteri, pemeriksaan Doppler pada pembuluh darah ibu.

c. Parameter biokimia, yang bisa memberi petunjuk tentang gangguan fungsi plasenta.

2. Obat-obatan terjangkau (murah dan mudah di dapat)

Tujuan untuk diagnosis dini adalah dengan memulai terapi pencegahan dengan pemberian $100 \mathrm{mg}$ asetilsalisilat (asetosal) sebelum 16 minggu kehamilan (pengurangan risiko preeklamsia berat: RR 0,$1 ; 95 \%$, KI $0,1-0,74)$. Jelas bahwa perhitungan risiko pada trimester pertama adalah metode yang paling efektif untuk mencegah preeklamsia. ${ }^{9}$ Terdapat resistensi asetosal yang diketahui pada 33\% wanita, minimal dosis pemberian setidaknya $100 \mathrm{mg} /$ hari. Kombinasi asetosal dan heparin dengan berat molekul rendah dalam pencegahan sekunder tampaknya membawa manfaat tambahan untuk hanya pemberian asetosal. ${ }^{10,11}$ Panduan organisasi kesehatan dunia World Health Organization (WHO) tahun 2011 memberikan acuan pemberian asetosal berkisar $75 \mathrm{mg} /$ hari sebelum minggu ke 20. Disamping itu World Health Organization (WHO) merekomendasikan kalsium 1,5 g sampai $2 \mathrm{~g}$ setiap hari untuk ibu hamil dengan asupan kalsium rendah. ${ }^{12}$ Suplementasi kalsium ( $\geq 1 \mathrm{~g} /$ hari) dikaitkan dengan penurunan risiko preeklamsi yang signifikan, terutama untuk wanita dengan diet rendah kalsium. ${ }^{13}$

Sebuah tinjauan bukti secara sistematis dilakukan oleh Satuan Tugas Pelayanan Pencegahan Amerika Serikat dan diterbitkan sebagai pedoman klinis pada bulan September 2014 oleh American College of Obstetricians and Gynecologists (ACOG), merekomendasikan penggunaan asetosal dosis rendah $80 \mathrm{mg}$ dimulai setelah $12 \mathrm{minggu}$ kehamilan pada wanita berisiko tinggi terjadinya preeklamsi. ${ }^{14}$ Wanita yang dianggap berisiko tinggi menurut ACOG jika ada satu atau lebih faktor risiko sebagai berikut:

a. Riwayat preeklamsi terutama jika disertai dengan hasil yang merugikan.

b. Kehamilan multifetus

c. Hipertensi kronis

d. Diabetes (tipe 1 atau tipe 2)

e. Penyakit ginjal

f. Penyakit autoimun

3. Terdapat panduan nasional praktik kedokteran tentang Preeklamsi (PNPK preeklamsi)

Panduan nasional praktik kedokteran tentang preeklamsi yang dikeluarkan oleh Perkumpulan obstetri dan ginekologi Indonesia (POGI) dan Kementerian Kesehatan. Setelah dikeluarkan PNPK ini selanjutnya dapat digunakan sebagai acuan untuk membuat panduan praktik klinik (PPK) di seluruh tempat pelayanan seluruh Indonesia termasuk di propinsi Jawa Barat. Panduan yang dikeluarkan berupa PNPK akan mempermudah layanan 
kesehatan untuk menangani preeklamsi dan diharapkan penanganannya menjadi seragam dan sama secara praktis klinis di seluruh Indonesia.

4. Rumah Sakit telah banyak berdiri (pemerintah dan swasta) di pelosok Jawa Barat

Tercatat sampai dengan bulan Juni 2017, jumlah rumah sakit di Jawa Barat tercatat sebanyak 328 rumah sakit. Berdasarkan kepemilikan, terdiri dari rumah sakit pemerintah sebanyak 70 rumah sakit $(21,34 \%)$, Sementara rumah sakit swasta terdapat sebanyak 258 rumah sakit $(78,66 \%){ }^{15}$

5. Tenaga kesehatan relatif mencukupi

Menurut data dari kementerian kesehatan tanggal 31 desember 2016 tercatat tenaga kesehatan yang bekerja di jawa barat sebagai berikut: Jumlah Spesialis Obstetri \& Ginekologi mencapai 1.063 orang, dokter umum 18.182 , bidan 17.629 orang (bidan di pusat kesehatan kesehatan primer 12.889), mencapai jumlah lebih dari cukup sampai di pelosok Jawa Barat meskipun mungkin penempatan di beberapa daerah tidak merata secara baik. ${ }^{5}$

\section{Konsep Program ZOOM}

\section{Kondisi saat ini}

a) Kasus Preeklamsi Tinggi

b) Angka Kematian Ibu akibat Preeklamsi tinggi

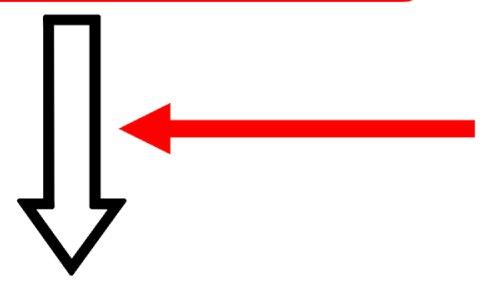

ZOOM (Target tercapai tahun ?)

(Zero mOther mOrtality PreeclaMpsia)

a) Masih terdapat kasus Preeklamsi dan berusaha untuk diturunkan

b) Jumlah kematian karena preeklamsi/Hipertensi dalam kehamilan $\mathrm{Nol}$

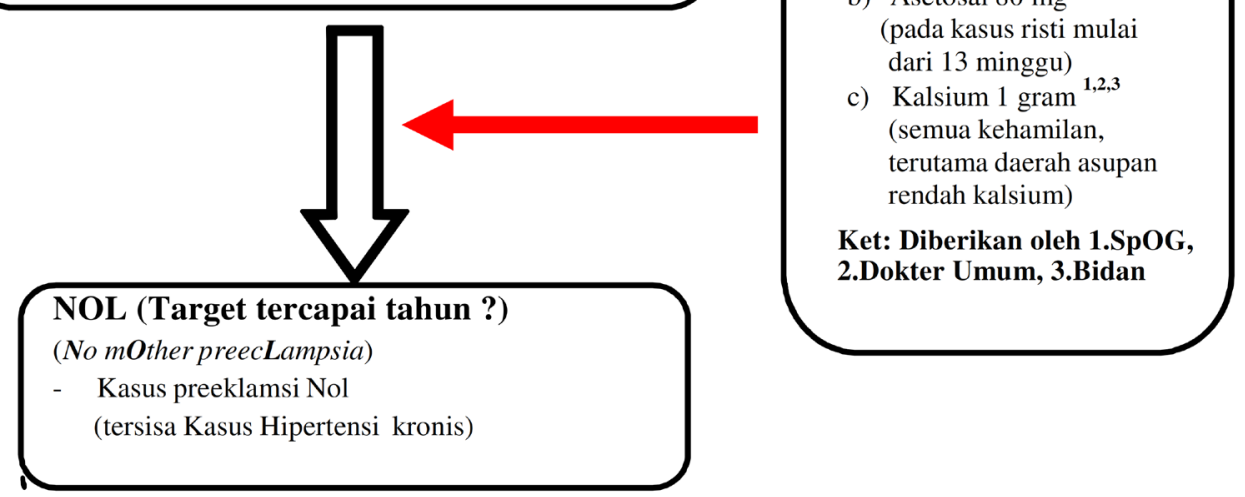

Gambar 1 Konsep Program Zoom 


\section{Tahapan dan langkah kegiatan}

1. Tahap pertama

a. Sosialisasi PNPK preeklamsia dari POGI pusat \& Kemenkes pada anggota POGI Jabar.

b. Sosialisasi \& reedukasi preeklamsi pada dokter puskesmas, dokter umum dan bidan seluruh jawa barat.

c. Workshop Pemeriksaan Doppler Arteri Uterina untuk program deteksi dini dan pencegahan.

2. Tahap kedua

a. Sosalisasi PNPK preeklamsi pada Rumah Sakit se Jawa Barat.

b. Sosialisasi PNPK preeklamsi pada seluruh Dinkes Kabupaten dan Kota se Jawa Barat termasuk Dinkes Provinsi.

3. Tahap ketiga

Edukasi eksekutif \& legislatif untuk mengeluarkan Peraturan daerah tentang preeklamsi. (Tujuan utama ZOOM : semua ibu hamil dengan hipertensidan risiko tinggi diwajibkan untuk bersalin di Rumah Sakit agar tidak ada kematian pada keadaan hipertensi dalam kehamilan)

\section{Daftar Pustaka}

1. World Health Organization. The 11 indicators of maternal, newborn and child health. Didapatkan dari: http://www.who.int/woman_child_accountability/progress_information/ recommendation2/en/ (diunduh 1 Maret 2018)

2. Pusat Data Kementerian Kesehatan Republik Indonesia.Angka kematian Ibu (AKI) Indonesia. Didapatkan dari: http://www.depkes.go.id/resources/download/pusdatin/profilkesehatan Indonesia/Profil-Kesehatan-Indonesia-2016.pdf (diunduh 1 Maret 2018)

3. Pemerintah Daerah Provinsi Jawa Barat. Angka Kematian Ibu melahirkan di Jabar. Didapatkan dari: http://www.jabarprov.go.id/index.php/news/17978/2016/06/23/AngkaKematian-Ibu-Melahirkan-di-Jabar-Tinggi .(diunduh 1 Maret 2018)

4. Pusat Data Kementerian Kesehatan Republik Indonesia. Hipertensi dalam Kehamilan. Didapatkan dari: http://www.depkes.go.id/resources/download/pusdatin/infodatin/ infodatin-ibu. (diunduh 1 Maret 2018)

5. Pusat Data Kementerian Kesehatan Republik Indonesia. Demografi Propinsi Jawa Barat. Didapatkan dari: http://www.depkes.go.id/resources/download/pusdatin/lain-lain/ Data\%20dan\%20Informasi\%20Kesehatan\%20Profil\%20Kesehatan $\% 20$ Indonesia $\% 20$ 2016\%20-\%20\%20smaller\%20size\%20-\%20web. (diunduh 1 Maret 2018)

6. Yu C K H, Smith G C S, Papageorghiou A T, Cacho A M, Nicolaides K H. An integrated model for the prediction of preeclampsia using maternal factors and uterine artery Doppler velocimetry in unselected low-risk women. Am J Obstet Gynecol. 2005; 193( 2): 429-36.

7. Sibai B, Dekker G, and Kupferminc M.Pre-eclampsia. The Lancet.2005;365(9461):785-99.

8. Steegers E, von Dadelszen A, Duvekot J J, Pijnenborg R. Pre-eclampsia. The Lancet.2010;376 (9741):631-44.

9. Bujold E, Morency A M, Roberge S, Lacasse Y, Forest J C, GiguèreY. Acetylsalicylic acid for the prevention of preeclampsia and intra-uterine growth restriction in women with abnormal uterine artery Doppler: a systematic review and meta-analysis. JOGC.2009; 31(9):818-26. 
10. Gris J C, Chauleur C, Molinari N. Addition of enoxaparin to asetosal for the secondary prevention of placental vascular complications in women with severe preeclampsia. The pilot randomized controlled NOH-PE trial. Journal of Thrombosis and Haemostasis.2011;106(6):1053-1061.

11. De Vries J I, Van Pampus M G, Hague W M, Bezemer P D, Joosten J H. Low-molecularweight heparin added to asetosal in the prevention of recurrent early-onset preeclampsia in women with inheritable thrombophilia: the FRUIT-RCT. Journal of Thrombosis and Haemostasis.2012; 10(1):64-72.

12. World Health Organization. Preeclampsia guidelines 2011. Didapatkan dari: http://apps. who.int/iris/bitstream/10665/44703/1/9789241548335_eng.pdf. (diunduh 1 Maret 2018)

13. Hofmeyr G, Lawrie TA, Atallah ÁN, Duley L, Torloni M. Cochrane Primary Review Group: Pregnancy and Childbirth Group, published 24 June 2014.

14. American College of Obstetricians \& Gynecologists (ACOG). Didapatkan dari: https://www. acog.org/Clinical-Guidance-and-Publications/Practice Advisories/Practice-AdvisoryLow-Dose-Asetosal-and-Prevention-of Preeclampsia-Updated-Recommendations. (diunduh 1 Maret 2018)

15. Pemerintah Daerah Jawa Barat. Fasilitas kesehatan propinsi Jawa barat. Didapatkan dari:http://www.jabarprov.go.id/index.php/artikel/detail_artikel/381/2017/07/11/SeluruhRumkit-di-Jabar-Harus-Terakreditasi. (diunduh 1 Maret 2018) 